\title{
Synthesis and Physical Properties of $n$-Heptane and 2,2,4-Trimethylpentane
}

\author{
Philip Pomerantz
}

\begin{abstract}
High-purity samples of $n$-heptane and 2,2,4-trimethylpentane have been prepared by synthetic methods and purified by fractional distillation for use as standards in the certification of primary reference fuels. One lot of $n$-heptane was used to prepare standard samples for the comparison of precision heat-capacity calorimeters. The details of the syntheses are presented, and the physical properties of these compounds are reported.
\end{abstract}

\section{Introduction}

The primary standards for the knock rating of gasolines are normal heptane and 2,2,4-trimethylpentane. These standards were adopted in 1930 , pure $n$-heptane being arbitrarily assigned the value of zero octane number and 2,2,4-trimethylpentane designated as 100 octane number. The octane numbers of solutions of 2,2,4-trimethylpentane in $n$-heptane are defined by the volume percentage of 2,2,4-trimethylpentane. The $n$-heptane and 2,2,4trimethylpentane used as primary reference fuels are produced commercially and submitted to the National Bureau of Standards for tests and the American Society for Testing. Materials certification of the samples is based on the Bureau's data. These tests comprise the determination of certain physical properties and the comparison of their detonation characteristics with those of high-purity $n$-heptane and 2,2,4-trimethylpentane, in accordance with specifications promulgated by the American Society for Testing Materials [1]. ${ }^{1}$ These specifications provide maximum tolerances for impurities, such that certified materials will have an octane number of $100 \pm 0.1$ for 2,2,4-trimethylpentane and $0 \pm 0.2$ for $n$-heptane.

In the early part of this cooperative program, the

1 Figures in brackets indicate the literature references at the enci of this paper. batches of $n$-heptane were prepared by chemical treatment and distillation from the resin of the Jeffrey pine, whereas batches of 2,2,4-trimethylpentane were prepared synthetically. So long as there were no significant changes in the methods of preparation, the physical properties of successive batchas correctly indicated their relative detonation characteristics [2].

In recent years, however, new methods of manufacture of the reference fuels were devised, and consequently, the nature and quantities of impurities were changed. This made necessary a new appraisal of the methods of testing reference fuels. It was found that the suitability of reference fuels could best be ascertained by comparison with very high purity compounds, and in this connection it was decided that the National Bureau of Standards should maintain a supply of high-purity $n$-heptane and 2,2,4-trimethylpentane. These materials would serve for use in comparison tests of ASTM primary reference fuels. The purpose of the present work was to prepare relatively large quantities of these compounds with a purity as high as practicable. These are designated as standard reference fuels.

A portion of the $n$-heptane prepared was further purified for use as a standard in the comparison of low-temperature calorimeters. This material is distributed as a heat-capacity standard by the Bureau

TABLE 1. Physical properties of n-heptane and 2,2,4-trimethylpentane

\begin{tabular}{|c|c|c|c|c|c|c|c|c|}
\hline \multirow{2}{*}{ Freezing point } & \multirow{2}{*}{ Purity } & \multirow{2}{*}{$\begin{array}{c}\text { Boiling } \\
\text { point at } \\
760 \mathrm{~mm} \\
\mathrm{Hg}\end{array}$} & \multirow{2}{*}{$\begin{array}{l}\text { Change in } \\
\text { bp with } \\
\text { pressure }\end{array}$} & \multicolumn{2}{|c|}{$\begin{array}{l}\text { Refractive index, } \\
n_{\mathrm{D}} \text { at- }\end{array}$} & \multicolumn{2}{|c|}{ Density at- } & \multirow{2}{*}{ Reference } \\
\hline & & & & $20^{\circ} \mathrm{C}$ & $25^{\circ} \mathrm{C}$ & $20^{\circ} \mathrm{C}$ & $25^{\circ} \mathrm{C}$ & \\
\hline \multicolumn{9}{|c|}{$n$-Heptane } \\
\hline $\begin{array}{l}\quad{ }^{\circ} \mathrm{C} \\
-90.60 \\
-90.609 \\
-90.595 \\
-90.604 \pm 0.005 \\
-90.604 \pm 0.005\end{array}$ & $\begin{array}{c}\text { Mole per- } \\
\text { cent }\end{array}$ & $\begin{array}{c}\circ \mathrm{C} \\
98.424 \\
98.426 \\
98.422 \\
\end{array}$ & $\begin{array}{c}{ }^{\circ} \mathrm{C} / m m \\
\mathrm{Hg}\end{array}$ & $\begin{array}{r}\text { 1. } 38764 \\
\text { 1. } 38764 \\
1.38756 \\
\end{array}$ & $\begin{array}{r}1.38511 \\
1.38517 \\
1.38519 \\
\end{array}$ & $\begin{array}{r}0.68368 \\
.68367 \\
.68366 \\
\end{array}$ & $\begin{array}{r}.67943 \\
.67949 \\
.67937 \\
\end{array}$ & $\begin{array}{l}{[3]} \\
{[5]} \\
{[14]} \\
\text { This work } \\
\text { Do. }\end{array}$ \\
\hline \multicolumn{9}{|c|}{$2,2,4$-Trimethylpentane } \\
\hline $\begin{array}{l}-107.37 \\
-107.396 \\
-107.365 \\
-107.388 \pm 0.005 \\
-107.388 \pm 0.005\end{array}$ & $\begin{array}{l}100.00 \\
99.998 \\
100.00\end{array}$ & $\begin{array}{r}99.233 \\
99.238 \\
99.236 \\
\end{array}$ & 0.0462 & $\begin{array}{l}1.39155 \\
1.39145 \\
1.39142\end{array}$ & $\begin{array}{l}1.38915 \\
1.38901 \\
1.38893\end{array}$ & $\begin{array}{r}0: 69189 \\
.69192 \\
.69188 \\
\end{array}$ & $\begin{array}{r}0.68778 \\
.68777 \\
.68783 \\
\end{array}$ & $\begin{array}{l}{[3]} \\
{[5]} \\
{[14]} \\
\text { This work } \\
\quad \text { Do. }\end{array}$ \\
\hline
\end{tabular}


to those participating in the Conference on Calorimetry [17].

Concurrently, the present work afforded samples of $n$-haptane and 2,2,4-trimethylpentane of known high purity for the determination of their physical constants. These data in turn enabled calculation of the freezing-point values for " $100 \%$ pure" material with greater accuracy. Table 1 lists the physical constants measured on the purest samples of $n$-heptane and 2,2,4-trimethylpentane obtained in this work, along with values reported in the literature.

\section{Preparation of Materials}

\section{1. $n$-Heptane (Synthetic)}

The preparation of $n$-heptane involved three chemical steps: Catalytic reduction of purified 2-heptanone to 2-heptanol; dehydration of the 2-heptanol to a mixture of $n$-heptenes; and hydrogenation of these heptenes to $n$-heptane. In each step, purification was effected by fractional distillation. The fractionating columns used have been described [9], but for convenience, the salient features of each are given in table 2. A charge of 52 gal of 2-heptanone (obtained from Carbide \& Carbon Chemicals Corp.) was fractionated in still 12 . This distillation was carried out at an initial reflux ratio of 50 to 1 , but as the distillation progressed, it was found that the distilled 2-heptanone contained a considerable quantity of water. This moisture is believed to have come from the dehydration of the aldols of 2-heptanone, which were formed under the influence of metallic oxides in the still pot. The presence of water was noted early in the distillation of the ketone fraction, and the take-off rate was subsequently increased so that the reflux ratio was about 20 to 1 . From this distillation, 30 gal of 2-heptanone, which beiled in the range $150^{\circ}$ to $151^{\circ} \mathrm{C}$, was obtained.
When a small sample of the 2 -heptanone, as received, was fractionated in an all-glass still, no water or material boiling over $200^{\circ} \mathrm{C}$ was obtained, as in the case of the large-scale distillation.

The distilled 2-heptanone was dried over anhydrous sodium sulfate and catalytically hydrogenated in several batches to 2-heptanol. These reductions were carried out in a 5-gal high-pressure autoclave at temperatures of $160^{\circ}$ to $180^{\circ} \mathrm{C}$ and a hydrogen pressure of 1,000 to $1,300 \mathrm{lb} / \mathrm{in}^{2}$, using nickel-onkieselguhr catalyst. The reaction proceeded smoothly, and the product. was tested for the presence of ketone by shaking a sample with a saturated solution of 2,4-dinitrophenylhydrazine in $2 \mathrm{~N}$ hydrochloric acid [10]. Each batch of 2-heptanone was hydrogenated until a negative test for ketone was obtained.

The catalyst was removed by filtration and the filtrate distilled in column 11 in several charges. From these distillations there were obtained 26.3 gal of 2-heptanol (bp $159.6^{\circ}$ to $159.7^{\circ} \mathrm{C}$ ). The first distillation of this series vielded a considerable quantity of 2 -heptanone in addition to the alcohol. The presence of ketone in the distillate was attributed to the action of very finely divided hydrogenation catalyst not removed by filtration. The high distillation temperature and prolonged boiling apparently caused appreciable dehydrogenation. The rest of the carbinol was subjected to a simple, fast distillation to remove the catalyst, before it was fractionally distilled. No difficulty was experienced in fractionating the material treated in this way. The properties of 2-heptanone, 2-heptanol, and other intermediates obtained in this work are given in table 3 .

The carbinol was dehydrated according to the method of Henne and Matuszak [7]. The distilled 2-heptanol (26.3 gal) was refluxed with $19 \mathrm{lb}$ of concentrated sulfuric acid for $1.5 \mathrm{hr}$ in a 50-gal glasslined reaction kettle. At the end of this time the

TABLE 2. Distillation columns

\begin{tabular}{|c|c|c|c|c|c|c|}
\hline Still & Type & Size & Material of construction & Packing & $\begin{array}{l}\text { Theoretical } \\
\text { number of } \\
\text { plates } \\
\text { (approx.) }\end{array}$ & $\begin{array}{l}\text { Pot capac- } \\
\text { ity }\end{array}$ \\
\hline $0_{\ldots}$ & \multirow{2}{*}{$\begin{array}{l}\text { Total reflux variable take-off } \\
\text { do }\end{array}$} & \multirow{5}{*}{$\begin{array}{l}\text { in. } \\
16 \text { by } 1 / 2 . \\
240 \text { by } 2 \\
600 \text { by } 4 \\
600 \text { by } 4 . \\
48 \text { by } 1.4 \\
400 \text { by } 3 .\end{array}$} & \multirow{5}{*}{ 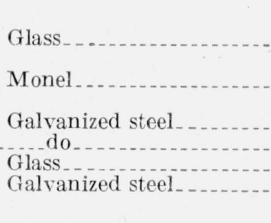 } & \multirow{5}{*}{$\begin{array}{l}\text { 3/6-in. stainless steel helices made from } \\
0.006 \text {-in. wire. } \\
3 / 32 \text {-in. stainless steel helices made from } \\
0.010 \text {-in. wire. } \\
\text { 3/8-in. unglazed porcelain raschig rings.... } \\
\text { do. do. } \\
\text { 3/6-in. glass helices... stainless steel helices made from } \\
0.010 \text {-in. wire. }\end{array}$} & 40 & \multirow{5}{*}{$\begin{array}{c}g a 7 . \\
0.1 \\
15 \\
\\
55 \\
55 \\
5.7 \\
30\end{array}$} \\
\hline 11. & & & & & 65 & \\
\hline 12 & ... do. & & & & 100 & \\
\hline & do - & & & & 100 & \\
\hline 28 & do. & & & & 100 & \\
\hline
\end{tabular}

TABLE 3. Physical properties of intermediates

\begin{tabular}{|c|c|c|c|c|c|c|}
\hline & \multirow{2}{*}{$\begin{array}{c}\text { Freezing } \\
\text { point }\end{array}$} & \multirow{2}{*}{$\begin{array}{c}\text { Boiling } \\
\text { point at } 760 \\
\mathrm{~mm} \mathrm{Hg}\end{array}$} & \multicolumn{2}{|c|}{ Density at- } & \multicolumn{2}{|c|}{ Refractive index, $n_{D}$ at- } \\
\hline & & & $20^{\circ} \mathrm{C}$ & $25^{\circ} \mathrm{C}$ & $20^{\circ} \mathrm{C}$ & $25^{\circ} \mathrm{C}$ \\
\hline $\begin{array}{l}\text { 2-Heptanone } \\
\text { 2-Heptanol } \\
\text { 2,4,4-Trimethyl-1-pentene } \\
\text { 2,4,4-Trimethyl-2-pentene }\end{array}$ & $\begin{array}{c}{ }^{\circ} \mathrm{C} \\
-93.508 \\
-103.321\end{array}$ & $\begin{array}{l}{ }^{\circ} \mathrm{C} \\
151.03 \\
159.7 \\
101.46 \\
104.94\end{array}$ & $\begin{array}{l}0.81570 \\
.8167 \\
.71512 \\
.72177\end{array}$ & $\begin{array}{c}0.81166 \\
.8129 \\
.71081 \\
.71755\end{array}$ & $\begin{array}{l}\text { 1. } 40878 \\
1.4203 \\
1.40857 \\
1.41611\end{array}$ & $\begin{array}{l}\text { 1. } 40566 \\
\text { 1. } 4182 \\
1.40592 \\
1.41337\end{array}$ \\
\hline
\end{tabular}


crude heptenes were distilled from the reaction kettle. During the distillation, the condenser water was maintained at $90^{\circ}$ to $95^{\circ} \mathrm{C}$, and the reflux temperature varied from $90^{\circ}$ to $105^{\circ} \mathrm{C}$. The distillation was continued until sulfur-dioxide fumes became quite strong and the temperature in the kettle began to rise rapidly. The organic distillate was washed first with 3-percent aqueous sodiumcarbonate, then with water, and finally dried over anhydrous sodium carbonate.

A charge of́ about 22 gal of́ dried organic distillate was iractionated in still 21 in order to separate the olefin from carbinol, which had steam-distilled. About 18 gal of olefin boiling below $100^{\circ} \mathrm{C}$ was obtained. The residue (4 gal), consisting mostly of carbinol, was dehydrated, using $2 \mathrm{lb}$ of concentrated sulfuric acid, and from this reaction about 2.6 additional gal of olefin was recovered. This material was dried, combined with the larger batch, and the entire charge fractionated in column 28. The distillation data showed that the olefin mixture consisted primarily of 1-hepteze and the cis and trans isomers of 2- and 3-heptene. As all of these hydrogenate to $n$-heptane, the main fraction of mixed olefins (14.5 gal boiling in the range $93.88^{\circ}$ to $97.78^{\circ} \mathrm{C}$ ) was hydrogenated at $150^{\circ} \mathrm{C}$ and 1,000 $\mathrm{lb} / \mathrm{ino}^{2}$, using nickel-on-kieselguhr catalyst. The "crude" $n$-heptane was percolated through silica gel and fractionated in column 11. Reiractive-index determinations were made on each iraction, and freezing points [12] were taken on selected samples. These data are shown in figure 1. The material indicated as cut $1-\mathrm{H}$ in figure 1 (about 20 liters) was reserved for preparation of calorimetric comparison standards.

\section{2. $n$-Heptane (from Commercial Products)}

The quantity of high-purity $n$-heptane prepared by synthesis was augmented by fractional distillation of a commercial product. The crude selected was "batch 28 -heptane" from the West Virgiaia Chlorine Products Co. (now the Westvaco Chemical Division of the Food Machinery Corp.). This product had previously been certified by the National Bureau of Standards for use as a primary reference fuel and had a purity of 99.71 mole percent. A
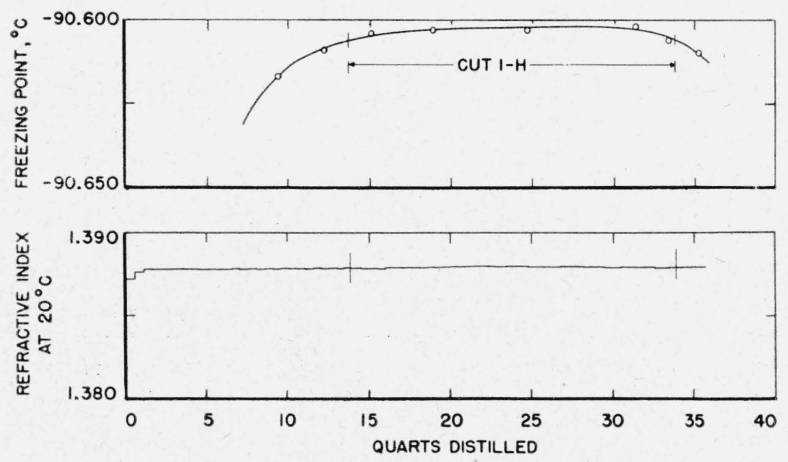

Figure 1. Freezing points and refractive indices of samples obtained from fractional distillation of synthetically prepared n-heptane. charge of $45 \mathrm{gal}$ of this material was distilled in several runs in stills 11 and 28 at a reflux ratio of 100 to 1 . The distillate fractions were percolated through silica gel beiore determination of physical properties. The ireezing points and relative refractive indices were measured by the techniques previously described [12]. Differences in refractive index between a selected sample and each of the other samples were measured by means of a Rayleigh interferometer. The results of one of these distillations is given in figure 2 . The middle portion, designated as cut $2-\mathrm{H}$ (17 gal), was reserved for preparation of standard $n$-heptane reference fuel.

\subsection{Trimethylpentane}

The 2,2,4-trimethylpentane was prepared in two steps: the isolation of high-purity 2,4,4-trimethyl-1pentene by fractional distillation of commercial diisobutylene, and the hydrogenation of this sample to 2,2,4-trimethylpeatane.

The large quantities of 2,4,4-trimethyl-1-pentene necessary ior this syinthesis and for other work were obtained by fractionation of commercial diisobutylene obtained from the Standard Alcohol Co. This iractionation was carried out in a manner similiar to that described previously [9]. Approximately 660 gal of diisobutylene was separated into three main concentrates, designated as cuts $\mathrm{A}$ to $\mathrm{C}$, by batch distillation in columns 12 and 13 at a reflux ratio of 15 to 1 . The data on these fractionations are summarized in table 4 .

Although both of the major isomers of diisobutylene may be hydrogenated to 2,2,4-trimethylpentane, the lower-boiling compound was chosen for this purpose because it could be obtained purer and in larger quantities. About 250 gal of cut B, fp $-94.17^{\circ} \mathrm{C}$, was redistilled in column 12 at a reflux ratio of 100 to 1 . From this distillation there was obtained 61 gal of material freezing above $-93.57^{\circ}$ C. This freezing point corresponds to a purity of $99.7+$ mole percent.

For the final distillation of olefin the 61 gal of $99.7+$ mole percent 2,4,4-trimethyl-1-pentene was divided into two portions of 15 and 46 gal, respectively. The 46 -gal portion was distilled at a reflux

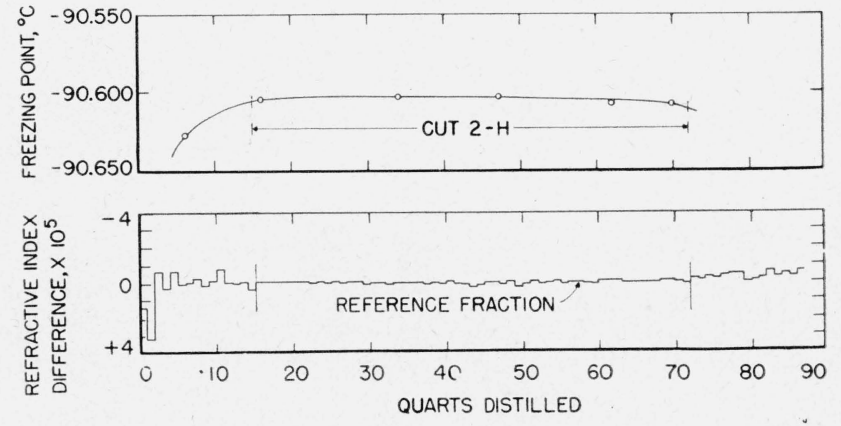

Figure 2. Freezing points and differences in refractive index of samples from fractional distillation of commercial $n$ heptane.

The difference in refractive index between each sample and the reference fraction indicated was measured by means of a Rayleigh interferometer. 
TABLE 4. Division of diisobutylene by preliminary distillation

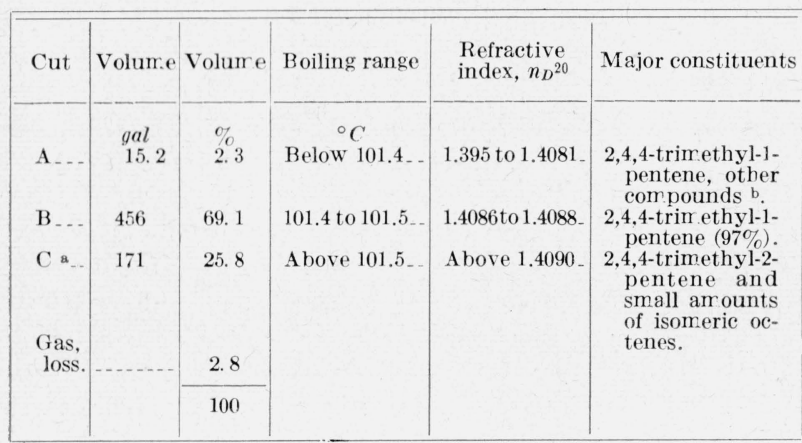

a Includes residue.

b Analysis of this cut by mass specorometer is as follows:

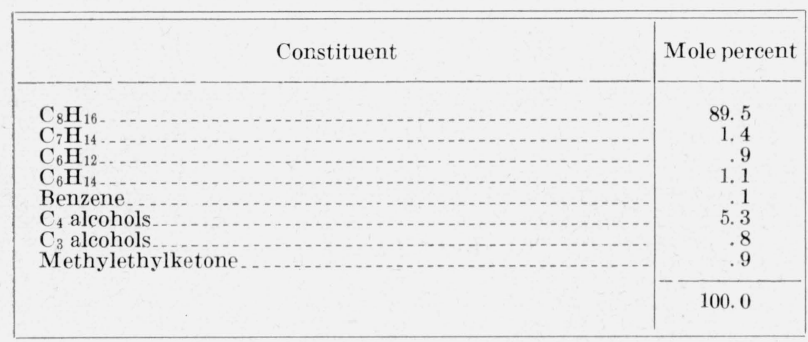

$\mathrm{C}_{4}$ alcohols were 2-butanol and tertiary butyl alcohol.

ratio of 150 to 1 in still 28. The 15 -gal portion, however, was subjected to an azeotropic distillation with 4 gal of methyl cellosolve [11] at a reflux ratio of 100 to 1 in still 11 . Both distillations vielded center-cut products of the same purity, which together totalled $29 \mathrm{gal}$. This material had a freezing point of $-93.52^{\circ} \mathrm{C}$, which corresponds to a purity of 99.8 mole percent.

The combined product of 99.8-mole-percent purity was catalytically hydrogenated at $160^{\circ} \mathrm{C}$ and 2,000 $\mathrm{lb} / \mathrm{in}^{2}$. The hydrogenated product was tested for unsaturation [16] and when completely hydrogenated was percolated through silica gel and distilled in column 28 at a reflux ratio of 150 to 1 . One-quart fractions were collected and passed through silica
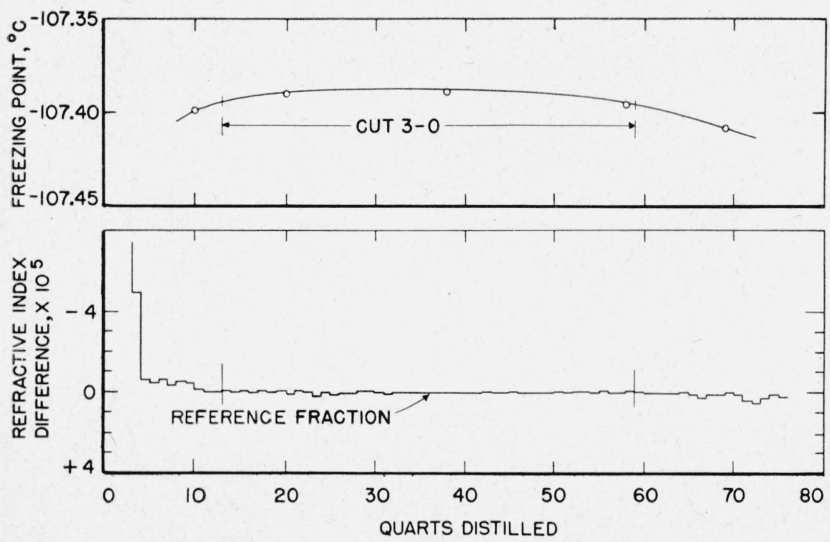

FIGURE 3. Freezing points and differences in refractive index of samples from fractional distillation of synthetic 2,2,4trimethylpentane.

The difference in refractive index between each sampie and the reference fraction indicated was measured by means of a Rayleigh interferometer. gel before the measurement of physical properties. The data from the distillation are shown in figure 3. The portion marked $3-\mathrm{O}$ in figure 3 was reserved for preparation of standard 2,2,4-trimethylpentane. The physical constants listed in table 1 for this compound were measured on material from this distillation having the highest freezing point.

\section{Determination of Purity}

The most common method of determining the purity of a substance is by comparing its freezing point with the freezing point of the substance containing zero impurity; from the depression of the freezing point and the cryoscopic constants, the purity of the material may be calculated. In order to apply this method, however, the freezing point for zero impurity must be accurately known. The latter value may be calculated [14], but such calculations are subject to error. To avoid the uncertainty in the determination of purity by cryoscopic measurements, recourse was made to purity determinations by calorimetric means [6].

The Thermodynamics Section of the Bureau has used a low-temperature calorimeter for determining with high accuracy the purities of various materials $[6,15]$. G. T. Furukawa and P. F. Wacker of the Thermodynamics Section used this instrument to determine the purity of several of the $n$-heptane and 2,2,4-trimethylpentane samples obtained in this work. The mole percentage of $n$-heptane in cut $1-\mathrm{H}$, prepared synthetically was found to be 99.983. A portion of cut $1-H$ was recrystallized three times by R. T. Leslie and W. E. Kuper, of the Pure Substances Section of the Bureau, to give a product of 99.9984 mole percent. The physical constants listed in table 1 for $n$-heptane were measured on this material. Cut 2- $\mathrm{H}$ had a purity of 99.985 mole percent. A portion of cut $2-\mathrm{H}$ was recrystallized, also by $\mathrm{R}$. T. Leslie, to yield a product of 99.9979 mole percent purity.

The purity of the synthetic 2,2,4-trimethylpentane, obtained by distillation alone (cut 3-O), was found to be 99.994 mole percent; the middle portion of this cut was 99.998 mole percent. As this purity was sufficiently high for the purposes at hand, no further purification was considered necessary.

\section{Analysis of Diisobutylene}

Previous work on diisobutylene $[9,18]$ has shown that this commercial olefin mixture consists predominantly of 2,4,4-trimethyl-1-pentene and 2,4,4-trimethyl-2-pentene, with lesser amounts of other isomers. The present work has extended this analysis to identify three other isomers present in very small amounts.

Of the cuts listed in table 4 of the preliminary distillation of diisobutylene, only cut $\mathrm{C}$ was further investigated. About 150 gal of this material was redistilled in several batches in column 13 . From these fractionations, two portions designated as 4-C1 and 4-C2 were obtained. These are shown 

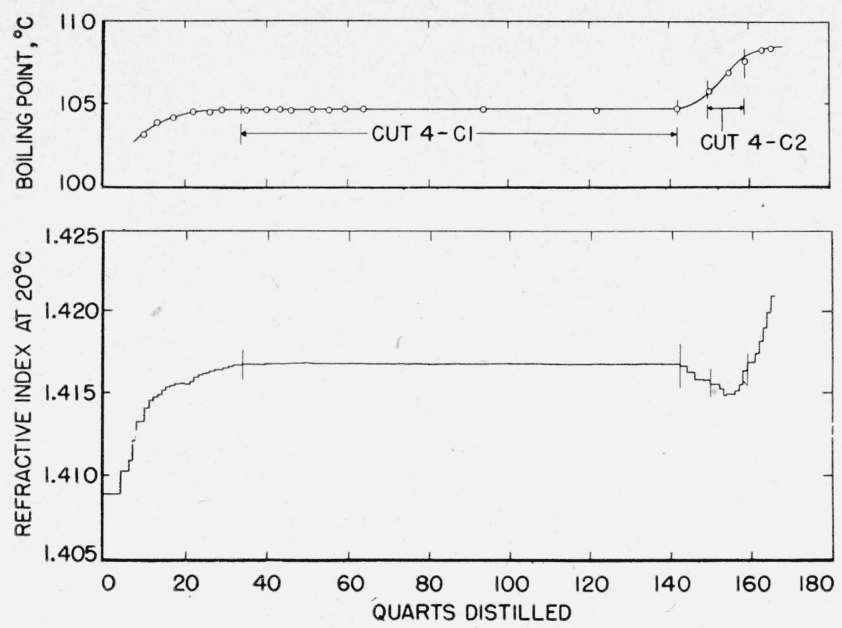

Figure 4. Refractive indices and boiling points of samples obtained from the fractional destillation of 2,4,4trimethyl-2-pentene.

in figure 4 , in which the data of one of the redistillations of cut $\mathrm{C}$ are illustrated. Cut 4-C1, 100 gal, was high-purity 2,4,4-trimethyl-2-pentene (99.3 mole percent). The properties of the best sample of this material are given in table 3.

Cut 4-C2 appeared to be a complex mixture; it was analyzed by the ozonolysis of a 0.5 -mole sample. The technique employed for this ozonolysis has been described [131. Both formaldehyde and acetone were found in the aqueous layer, and acetaldehyde was found in the ether trap. Formaldehyde was identified by means of its dimethone derivative, $\mathrm{mp} 188^{\circ}$ to $189^{\circ} \mathrm{C}$; acetone was identified as dibenzalacetone, $\mathrm{mp} 111^{\circ}$ to $112^{\circ} \mathrm{C}$; and acetaldehyde was identified by means of the aldehyde ammonia complex, $\mathrm{mp} 85^{\circ}$ to $87^{\circ} \mathrm{C}$. The oil from hydrolysis of the ozonide was fractionated in still 9 . The properties and methods of identification of the several fractions are shown in table 5. The last two derivatives listed were quite impure, but the fact that admixture of the known substance raised the melting point of each was considered a fair indication that the ketone was correctly identified. The latter consideration is strengthened by the fact that admixture of derivatives of isomeric ketones lowered the melting point in each case. The ketones and aldehydes identified by this means indicate that the major components of cut $4-\mathrm{C} 2$ were (1) 2,4,4 trimethyl-2-pentene, (2) 5,5 dimethyl 2-hexene, (3) 2,3,4-trimethyl-1-pentene, and (4) 2,3,3-trimethyl-1-pentene. There were undoubtedly smaller quantities of other hydrocarbons present, but these were not identified. The residue from the distillation of cut $\mathrm{C}$ was fractionated in column 9 and found to contain only 3,4,4-trimethyl.2-pentene and 2,3,4-trimethyl-2-pentene.

The analysis of the diisobutylene is given in table 6 and is based primarily upon distillation data.

TABLE 6. Analysis of diisobutylene

\begin{tabular}{|c|c|}
\hline Constituent & $\begin{array}{c}\text { Percentage } \\
\text { (by volume) }\end{array}$ \\
\hline $\begin{array}{l}\text { 2,4,4-trimethyl-1-pentene } \\
\text { 2,4,4-trimethyl-2-pentene } \\
\text { 3,4,4-trimethyl-2-pentene } \\
\text { 2,3,4-trimethyl-2-pentene } \\
\text { 2,3,3-trimethyl-1-pentene } \\
\text { 2,3,4-trimethyl-1-pentene } \\
\text { 5,5-dimethyl-2-hexene, and others } \\
\text { Alcohols, ketones, and low-boiling materials }\end{array}$ & $\begin{array}{r}80.7 \\
17.6 \\
1.1 \\
.4 \\
.2\end{array}$ \\
\hline & 100.0 \\
\hline
\end{tabular}

\section{Conclusions and Discussion of Results}

Over 22 gal of $n$-heptane and 12 gal of 2,2,4-trimethylpentane have been prepared in very high purity for use as calorimetric standards and standard reference fuels.

The purest sample of $n$-heptane was prepared by crystallization of the distilled product. This material was percolated through silica gel before making the purity measurements and found to have a freezing point of $-90.604 \pm 0.005^{\circ} \mathrm{C}$ and a purity of 99.9984 mole percent by calorimetric measurements. Using the freezing point-depression of 0.20 $\operatorname{deg} \mathrm{C} /$ mole percent [2], the freezing point of $n$-hep-

TABLE 5. Results from ozonolysis of Cut $4^{-C 2}$

\begin{tabular}{|c|c|c|c|c|c|}
\hline Compound present & $\begin{array}{l}\text { Carbonyl compound } \\
\text { identified a }\end{array}$ & $\mathrm{bp}$ & $\begin{array}{l}\text { 2,4-Dinitrophenyl- } \\
\text { hydrazone mp }\end{array}$ & Mixed mp & Dimethone, $\mathrm{mp}$ \\
\hline $\mathrm{C}-\underset{!}{\mathrm{C}}=\stackrel{\mathrm{C}}{\mathrm{C}}-\mathrm{C}=\mathrm{C}-\mathrm{C}$ & $\mathrm{C}-\underset{\mathrm{C}}{\mathrm{C}}-\mathrm{C}$ & $\begin{array}{l}{ }^{\circ} \mathrm{C} \\
60 \text { to } 63\end{array}$ & $\begin{array}{l}\quad{ }^{\circ} C \\
206 \text { to } 207 \\
207[8]\end{array}$ & $\begin{array}{c}{ }^{\circ} \mathrm{C} \\
206 \text { to } 207\end{array}$ & ${ }^{\circ} \mathrm{C}$ \\
\hline C & C & & & & \\
\hline$\underset{\mathrm{C}}{\mathrm{C}-\mathrm{C}}-\mathrm{C}-\mathrm{C}=\mathrm{C}-\mathrm{C}$ & $\underset{\mathrm{C}}{\mathrm{C}-\mathrm{C}}-\mathrm{C}-\mathrm{CHO}$ & 102 to 103.5 & $\begin{array}{l}144 \text { to } 145 \\
147[4]\end{array}$ & & $\begin{array}{l}164.5 \text { to } 166 \\
167[4]\end{array}$ \\
\hline $\begin{array}{lll}\mathrm{C} & \mathrm{C} & \mathrm{C} \\
& \mathrm{C} & \mathrm{l}\end{array}$ & $\begin{array}{lll}\mathrm{C} & \mathrm{C} & \mathrm{C}\end{array}$ & & & & \\
\hline $\mathrm{C}-\mathrm{C}-\mathrm{C}-\mathrm{C}=\mathrm{C}$ & $\mathrm{C}-\mathrm{C}-\mathrm{C}-\mathrm{C}=\mathrm{O}$ & 130 to 131 & $\begin{array}{l}90 \text { to } 95 \\
100 \text { to } 102[13]\end{array}$ & 94 to 97 & \\
\hline $\mathrm{C}-\mathrm{C}-\underset{\mathrm{C}}{\stackrel{\mathrm{C}}{\mathrm{I}}-\mathrm{C}}=\mathrm{C}$ & $\begin{array}{c}\mathrm{C}-\mathrm{C}-\mathrm{I}-\mathrm{C}-\mathrm{C}=\mathrm{C} \\
\mathrm{I} \\
\mathrm{C}\end{array}$ & 132 to 133 & $\begin{array}{l}80 \text { to } 88 \\
111 \text { to } 112[9]\end{array}$ & $\varepsilon 8$ to 95 & \\
\hline
\end{tabular}

a Only the larger fragments from the ozonolysis are included here. The identifications of formaldehyde, acetaldehyde, and acetone are described in the text. 
tane containing zero impurity in air at 1 -atm pressure is $0.0003 \mathrm{deg} \mathrm{C}$ higher. However, this figure is insignificant as the precision of measurement of the freezing point $( \pm 0.005 \mathrm{deg} C)$ is larger by an order of magnitude. The freezing point of "100-percentpure" $n$-heptane, therefore, is $-90.604 \pm 0.005^{\circ} \mathrm{C}$, when measured by the method described in [12].

The purest sample of 2,2,4-trimethylpentane had a freezing point of $-107.388 \pm 0.005^{\circ} \mathrm{C}$ and a purity of 99.998 mole percent. The freezing point for 2,2,4-trimethylpentane containing zero impurity may be calculated likewise to be very nearly the same as that observed for this very high-purity sample.

Grateful acknowledgment is made to G. T. Furukawa and P. F. Wacker, of the Thermodynamics Section of the Bureau, for their work on the purity determinations of several fractions, and $\mathrm{R}$. T. Leslie and W. E. Kuper, of the Pure Substances Section, for their work in recrystallizing several of these.

The author expresses his appreciation to D. B Brooks, T. W. Mears, A. Fookson, E. H. Rich, and F. L. Howard for their helpful suggestions and assistance in preparing the standard reference fuels and their intermediates.

\section{References}

[1] ASTM Manual of Engine Test Method for Rating Fuels. March 1948 , page 111 , and 1950 appendix, page 12 (Published by the American Society for Testing Materials, Philadelphia 3, Pa.).
[2] D. B. Brooks, R. B. Cleaton, and F. R. Carter, J. Research NBS 19, 319 (1937) RP1027.

[3] D. B. Brooks, F. L. Howard, and H. C. Crafton, Jr., J. Research NBS 24, 33 (1940) RP1271.

[4] H. Brunner and E. H. Farmer, J. Chem. Soc. 1039 (1937).

[5] A. F. Forziati, A. R. Glasgow, Jr., C. B. Willingham, and F. D. Rossini, J. Research NBS 36, 129 (1946) RP1695.

[6] G. T. Furukawa, D. C. Ginnings, R. E. McCoskey, and R. A. Nelson, J. Research NBS 46, 195 (1951) RP2191.

[7] A. L. Henne and A. H. Matuszak, J. Am. Chem. Soc. 66, 1649 (1944).

[8] F. L. Howard, T. W. Mears, A. Fookson, and P. Pomerantz, J. Am. Chem. Soc. 68, 2121 (1946).

[9] F. L. Howard, T. W. Mears, A. Fookson, P. Pomerantz, and D. B. Brooks, J. Research NBS 38, 365 (1947) RP1779.

[10] H. A. Iddles and C. E. Jackson, Ind. Eng. Chem., Anal. ed. 6, 454 (1934).

[11] B. J. Mair, A. R. Glasgow, Jr., and F. D. Rossini, J. Research NBS 2\%, 39 (1941) RP1402.

[12] T. W. Mears, A. Fookson, P. Pomerantz, E. H. Rich, C. S. Dussinger, and F. L. Howard, J. Research NBS 44, 299 (1950) RP2079.

[13] P. Pomerantz, T. W. Mears, and F. L. Howard, J. Research NBS 42, 617 (1949) RP1999.

[14] Selected values of properties of hydrocarbons, NBS Circular C461, p. 388 (1947).

[15] R. B. Scott, C. H. Meyers, R. D. Rands, Jr., F. G. Brickwedde, and N. Bekkedahl, J. Research NBS 35, 39 (1945) RP1661.

[16] R. L. Shriner and R. C. Fuson, Identification of organic compounds, 3d ed., p. 23 (John Wiley and Sons, Inc., New York, N. Y., 1935).

[17] The Fourth Meeting of the Conference on Low Temperature Calorimetry, Chem. Eng. News 27, 2772 (1949).

[18] C. O. Tongberg, J. D. Pickens, M. R. Fenske, and F. C. Whitmore, J. Am. Chem. Soc. 54, 3706 (1932).

Washington, August 22, 1951. 